Bulletin UASVM serie Agriculture 69(2)/2012

Print ISSN 1843-5246; Electronic ISSN 1843-5386

\title{
Population Access to Waste Collection Services :Urban vs Rural Areas in Romania
}

\section{Florin Constantin MIHAI}

Faculty of Geography and Geology, "Alexandru Ioan Cuza" University of Iasi, 35 B-dul Carol I, Nr. 20 A, RO-700505, Iasi, Romania; mihai.florin86@yahoo.com

\begin{abstract}
This paper aims a comparative analysis at county level concerning urban and rural population access to sanitation services in the context of EU accession. Partially coverage of population to such services contributes to illegal dumping of waste generated and uncollected.Furthermore, waste management facilities are inappropriate, particularly in small cities or rural areas. Comparative analysis of urban vs. rural population served by waste collection services using thematic cartography highlights on the one hand the existing disparities within a county and on the other hand reflects the regional disparities across Romania.The demographic, socioeconomic and geographic differentiations between urban and rural areas amplify these gaps that prevent from implementation of an effective waste management system at national scale.Thematic maps highlights that urban population is not fully covered by sanitation services while in rural areas less than half of population has access to these services.Also,in some counties, vulnerability to illegal dumping is high in both rural and urban areas.
\end{abstract}

Keywords: sanitation services,urban vs rural areas,illegal dumping,waste mangement

Introduction. Full access of population to sanitation services is a key factor in providing a sustainable waste management in Romania.Mihai et al. (2012a), Mihai et al. (2012b) have pointed out that accessibility to these services is partially, having a slow growth in the period 2003-2008. Waste generated and uncollected are uncontrolled disposed in urban ares.(Mihai et al.2011) Open dumping in rural regions and small cities was the most common solution adopted by local authorities until the closure of these sites (16 july 2009).European funds currently financing several projects to implement integrated soild waste management systems at the county level which will lead to extension of sanitation services in urban and rural areas.

Aims and objectives. This paper aims a comparative analysis at county level concerning urban and rural population access to sanitation services in the context of EU accession.Comparative analysis of urban vs. rural population served by waste collection services using thematic cartography highlights on the one hand the existing disparities within a county and on the other hand reflects the regional disparities across Romania.

Materials and methods. There has been a database at the Romanian counties level on urban and rural population with no access to sanitation services, these data being provided by the Regional Environmental Protection Agencies. The data were mapped using proportional circles method (comparing two absolute values) resulting two thematic maps for the years 2003 and 2008

Results and Discussion Partially coverage of population to such services contributes to illegal dumping of waste generated and uncollected.Furthermore,waste management facilities are inappropriate,particularly in small cities or rural areas.The demographic, socioeconomic and geographic differentiations between urban and rural areas amplify these gaps that prevent from implementation of an effective waste management system at national scale. The lack or poor solid waste management facilities from well- 
populated rural areas is reflected in higher number of rural inhabitants without sanitation services from eastern and southern counties of country (Iaşi,Vaslui,Călăraşi Teleorman,Olt,Dolj) for both studied years.Also,this situation is occuring in counties which overlaps on Carpathian Arch (Suceava,Neamț Bacău,Vrancea,Buzău,Prahova,Argeş, Vâlcea). Total population of these counties without access to sanitation from 2003 and 2008 highlights the lack of concrete measures on development of waste management sector.Rural areas have in most counties limited access to sanitation services comparing to urban settlements.However,at county level number of population unserved is more balanced between urban and rural areas from following counties: Hunedoara,Alba and Sibiu.

Comparative analysis between 2003-2008 shows that extension of sanitation services in urban areas is more significant than rural areas.

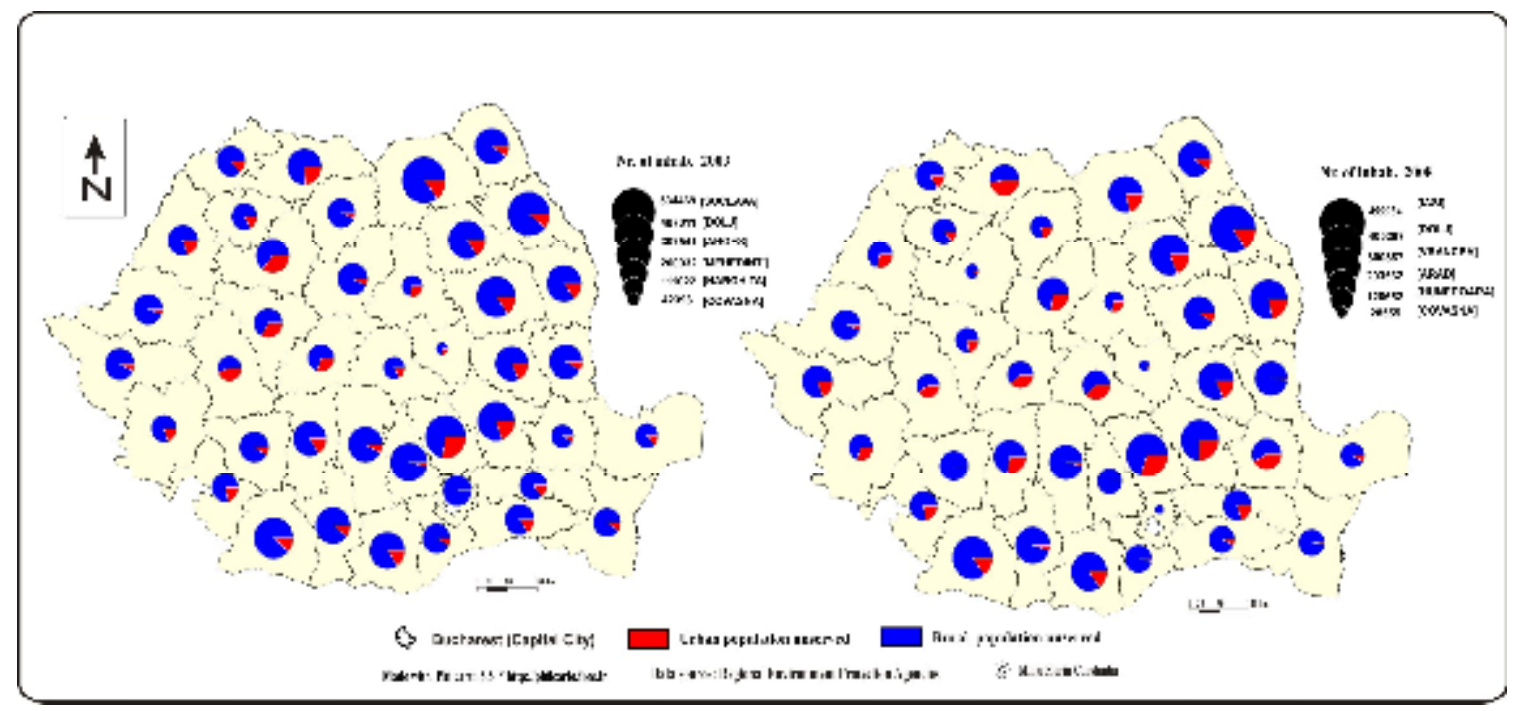

Fig. nr.1 Comparative analysis of population unserved (2003 and 2008)

However, in some counties the access to sanitation services of urban population is lower than 2003 such as Galaţi,Maramureş or Braşov.Major changes in urban and rural regions is noticed in Cluj or Ilfov county where the influence of capital city from proximity is significant in the development of private sector in waste management services. Full access of urban populations to waste collections services is noticed only in two counties ( Ilfov and Gorj) in 2008.On the other side,sparsely populated counties (Harghita and Covasna) and geographical conditions (human settlements concentrated in mountain depressions) favored the extension of these services from urban to rural regions in the proximity.

Conclusion. Thematic maps highlights that urban population is not fully covered by sanitation services while in rural areas less than half of population has access to these services.Also,in some counties, vulnerability to illegal dumping is high in both rural and urban areas.Demographic features of urban and rural population within a county reflect the disparities between Romanian counties.Poor solid waste management systems which prevailed in rural regions highlight the limited access of local population to waste collections services which lead to illegal dumping of waste uncollected. 


\section{REFERENCES}

1. Mihai,F.C.,A.Lămăşanu and L.Apostol (2012).Regional disparities in urban population access to sanitation services.Case study:Romania.Mediterranean Journal of Social Sciences,Special issue, 3(6): 273-279

2. Mihai,F.C., L.Apostol, A.Lămăşanu and A.A.Ghiurcă (2012).Spatiotemporal analysis of Romania's rural population access to sanitation services in the context of EU accession,Proc. $12^{\text {th }}$ International Multidisciplinary Scientific GeoConference SGEM 5: 787-792

3. Mihai, F.C., A.A.Ghiurcă, A.Lămăşanu (2011).Estimation of urban waste generated and uncollected in Romania,Analele Universitati Oradea Fascicula:Protectia Mediului, 17(2) :719-724 